\title{
Control of grain size by second phase particle additions in novel HSLA steels
}

\author{
C. A. Khoo*, W S. Tai* and G. Fourlaris* \\ *Materials Research Centre, School of Engineering, University of Wales Swansea, Swansea, SA2 \\ 8PP, UK.
}

High Strength Low Alloy (HSLA) strip steels have extensive applications in the automotive industry, due to their excellent combination of strength, toughness and formability characteristics. With the drive to produce environmentally friendly cars, the need of developing novel high strength strip steel products, is ever increasing. Development of novel high strength strip steel grades would permit the down-gauging of automotive steel components, leading to lighter, fuel efficient and safer automobiles [1].

Coarsening of second phase particles in a metallic matrix plays an important part in many metallurgical phenomena, such as the tempering of martensite, grain growth, precipitation hardening and creep deformation. The broad definition of the particle coarsening (i.e.: Ostwald ripening) process relates to the growth of second phase particles without significant change in the matrix solute content. The process thus differs from the precipitation processes where second phase particles nucleate and grow by depletion of the relevant matrix solute [2-4].

The purpose of the present study is to study the control of austenite grain size via second phase particle additions, based on combined titanium and vanadium microalloy additions. Such information is readily available for commercial HSLA grades based on titanium only, niobium or titanium-niobium microalloying additions [5,6], however limited knowledge is available on the combined effects of titanium and vanadium microalloy additions. Processing of HSLA strips steels, aims to produce a fine austenite grain size, resulting in the subsequent formation of a fine primarily ferritic product.Two experimental titanium and titanium-vanadium HSLA grades were studied, as part of this comparative study. For the production of the two experimental alloys, high purity materials were used and the melting was performed in a vacuum induction furnace .

Samples of the experimintal HSLA grades were austenitised within the temperature range of 900$1100^{\circ} \mathrm{C}$ for $1 \mathrm{~h}$, followed by rapid water quenching. A vacuum furnace has been employed for the heat treatments to avoid any decarburisation effects on the thin strip steel samples.

The present study confirmed that vanadium carbide precipitates succesfully control the austenite grain size at low austenitisation temperatures $\left(900-950^{\circ} \mathrm{C}\right)$, by effectively pinning the austenite grain boundaries (figs. 1 and 2). However, at higher austenitisation temperatures (in excess of $1000^{\circ} \mathrm{C}$ ), rapid dissolution of vanadium carbide does occur and the importance of titanium nitride formation in controlling the austenite grain size, in both experimental grades, becomes evident (fig 3). Titanium nitride with its very low dissolution rates and high stability at elevated temperatures prevents excessive austenite grain coarsening.

It has been concluded that combined titanium-vanadium additions are beneficial in maintaining a fine austenite grain size (of the order of $10 \mu \mathrm{m}$ ), during the finishing passes of the experimental titanium-vanadium HSLA steel. Austenite grain refinement during the finishing passes has been attributed to the combined effects of coarse titanium nitrides, fine titanium carbides, as well as very fine interphase precipitates of vanadium carbide (fig. 2).

\section{References}


[1] ULSAB-AVC, Engineering Summary Report, 2002.

[2] I.M. Lifshitz and V.V.Slyozov, J.Phys.Chem.Solids, 1961, $\underline{\mathbf{1 9}}$, p.35.

[3] C.Wagner, Z.Electrochemie, 1961, $\underline{\mathbf{6 5}}$, p.243.

[4] H Fischmeister and G.Grimvall, Materials Sci.Res., 1973, ㄸ, p.119.

[5] H Adrian, "Microalloying 95", I.S.S, Pittsburgh, 1995, p.285.

[6] T.Gladman, "The Physical Metallurgy of Microalloyed Steels", Inst. of Materials, London, 1997.
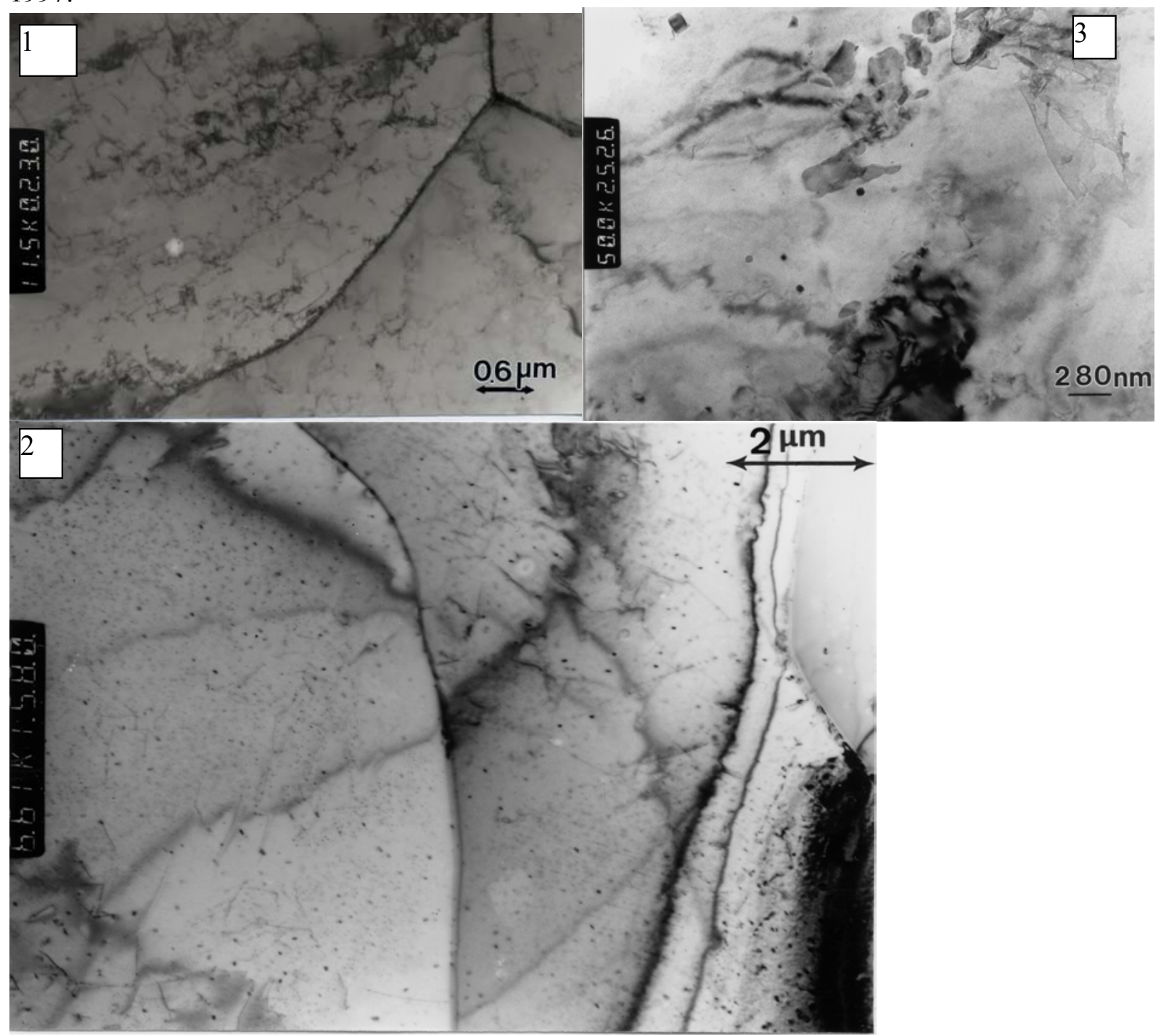

Fig.1: A bright field TEM micrograph of fine titanium nitride precipitation, following rapid cooling from the finishing temperature (Ti only HSLA steel).

Fig.2: A bright field TEM micrograph of titanium nitride, titanium carbide and very fine interphase precipitation of vanadium carbide, following rapid cooling from the finishing temperature (Ti-V HSLA steel).

Fig.3: A bright field TEM micrograph of titanium nitride precipitation within ferrite, produced in samples of the titanium-vanadium HSLA strip steel austenitised at $1050^{\circ} \mathrm{C}$ for $1 \mathrm{~h}$. 